\title{
Porównanie wymagań norm PN-M-69770 oraz PN-EN ISO 17636-1
}

\author{
A comparison of the requirements of standards PN-M-69770 \\ and PN-EN ISO 17636-1
}

\section{Streszczenie}

W lipcu 2002 r. została wycofana, używana od 1961 roku norma PN-M-69770, dotychczas obowiązująca przy badaniach złączy spawanych. Ponad rok wcześniej, w kwietniu 2001 roku wprowadzono w Polsce do użycia PN-EN 1435 dotyczącą techniki badań radiograficznych złączy spawanych (została ona zastąpiona w 2013 przez PN-EN ISO 17636-1). Jednak pomimo upływu piętnastu lat przepisy obowiązujące "za starych czasów" nadal są używane przy kontroli radiograficznej spoin konstrukcji wykonywanych obecnie oraz przy badaniach eksploatacyjnych.

W artykule porównano zakresy stosowania obu przepisów w celu zbadania możliwości zastąpienia PN-M-69770 normą PN-EN-ISO 17636-1. Porównanie ograniczono do promieniowania $X$ uzyskanego $z$ lamp rentgenowskich o napięciu do $400 \mathrm{kV}$.

Słowa kluczowe: badania nieniszczące; radiografia; PN-M-69770; PN-EN ISO 17636-1

\begin{abstract}
In July 2002, after using since 1961 to research of welded connection, standard PN-M-69770 was withdrawn. More than year before this date, in April 2001, made to use in Poland standard PN-EN 1435 on technique of radiographic research of welded connection (it was replaced in 2013 by PN-EN ISO 17636-1). However, despite the passage of fifteen years, the rules in force in "the old days" are still used during radiographic control of welded structures made now and during tests in-service.

In the article were compared scopes of the two provisions in order to explore the possibility of replacing standard PN-M-69770 by standard PN-EN-ISO 17636-1. A comparison limited to radiation $\mathrm{X}$ obtained from $\mathrm{X}$-ray tubes with a voltage to the $400 \mathrm{kV}$.
\end{abstract}

Keywords: non-destructive testing; radiography; PN-M-69770; PN-EN ISO 17636-1

\section{Wstęp}

W 1924 r. na podstawie uchwały podjętej na posiedzeniu Komitetu Technicznego dla normalizacji wyrobów przemysłowych oraz ich dostawy powstaje Polski Komitet Normalizacyjny (PKN), a Polska Norma (PN) jest uznana za oficjalny dokument do dobrowolnego stosowania. W 1949 r. Ustawa o Polskim Komitecie Normalizacyjnym wprowadza normy jako dokumenty do obowiązkowego stosowania. W 1993 r. Polski Komitet Normalizacyjny (PKN) jest reaktywowany na mocy przepisów Ustawy o normalizacji z dnia 3 kwietnia 1993 r. Ustawa wprowadza dobrowolny system normalizacyjny zgodny z systemem europejskim. Polskie Normy ponownie zyskują status dokumentów do dobrowolnego stosowania [1].

Jako dokumentacja dobrowolnie stosowana normy stanowią $\mathrm{w}$ tym podejściu odzwierciedlenie aktualnego stany wiedzy technicznej. Wraz z rozwojem techniki i poziomu wiedzy zmianie ulegają stosowane standardy, czego następstwem jest stworzenie nowych i wycofaniem dotych- czas stosowanych przepisów. Należy podkreślić fakt, że norma wycofana pozostaje w dalszym ciągu normą "zgodną" i nie ma formalnego zakazu postępowania zgodnie z normą wycofaną, której rozwiązania nie są błędne. Podmioty realizujące projekt określają który ze standardów chcą stosować - co jest w pełni zgodne z zasadą dobrowolnego stosowania dokumentów.

W lipcu 2002 r. została wycofana, używana od 1961 roku norma PN-M-69770, dotychczas obowiązująca przy badaniach złączy spawanych. Ponad rok wcześniej, w kwietniu 2001 roku wprowadzono w Polsce do użycia PN-EN 1435 dotyczącą techniki badań radiograficznych złączy spawanych (została ona zastąpiona w 2013 przez PN-EN ISO 17636-1). Jednak pomimo upływu piętnastu lat przepisy obowiązujące „za starych czasów” nadal są używane przy kontroli radiograficznej spoin konstrukcji wykonywanych obecnie oraz przy badaniach eksploatacyjnych.

Mgr inż. Konrad Ogonowski - Laboratorium Badań Nieniszczących „AR” w Szczecinie; mgr inż. Małgorzata Ogonowska - Akademia Morska w Szczecinie.

Autor korespondencyjny/Corresponding author: kogon@wp.pl 
W artykule porównano zakresy stosowania obu przepisów w celu zbadania możliwości zastąpienia PN-M-69770 normą PN-EN-ISO 17636-1.

Porównanie ograniczono do promieniowania X uzyskanego z lamp rentgenowskich o napięciu do 400 kV.

\section{Zakres norm}

Zakres stosowania normy PN-M-69770 ograniczono do grubości ścianek do $100 \mathrm{~mm}$ stali i powszechnie w Polsce używanych źródeł promieniowania: promieniowanie aparatów rentgenowskich do 400 kV oraz źródeł promieniowania gamma Ir 192, Cs 137 i Co 60 [2].

PN-EN ISO17636-1 przewiduje badania różnych metali (miedź, stal, aluminium, tytan i ich stopy), stali do grubości $150 \mathrm{~mm}$, promieniowaniem X uzyskanym w aparatach rentgenowskich do $1000 \mathrm{kV}$ oraz izotopami Yb 169, Tm 170, Se 75, Ir 192 i Co 60. Ponadto przepisy przewidują użycie źródeł promieniowania X o energii od $1 \mathrm{MeV}$ do ponad $12 \mathrm{MeV}$ [3].

\section{Klasyfikacja metod badań}

PN-M-69770 dzieli metody badań na dwa główne rodzaje: badania przez jedną ściankę i badania przez dwie ścianki. Każda z tych metod jest podzielona na kilka odmian.

Pierwszą metodę podzielono na:

- metodę podstawową - badanie spoiny prostej, obustronnie dostępnej;

- metodę zewnętrzną - badanie spoiny zakrzywionej, obustronnie dostępnej;

- metodę centryczną - badanie spoiny obwodowej, obustronnie dostępnej, źródło promieniowania umieszczone w środku krzywizny spoiny;

- metodę ekscentryczną - badanie spoiny obwodowej, obustronnie dostępnej, źródło promieniowania umieszczone wewnątrz badanego przedmiotu w płaszczyźnie przechodzącej przez obwód spoiny o odległości optymalnej od błony.

Z kolei druga metoda podzielona jest na:

- metodę podstawową przesłoniętą - badanie spoiny prostej niedostępnej od strony wewnętrznej;

- metodę obwodową - badanie spoiny obwodowej, niedostępnej od strony wewnętrznej, źródło promieniowania umieszczone na obwodzie spoiny lub w niewielkiej od niej odległości;

- metoda półeliptyczna - badanie spoiny obwodowej, niedostępnej od strony wewnętrznej, źródło promieniowania znacznie oddalone od spoiny i nieco przesunięte względem płaszczyzny spoiny przechodzącej przez obwód, błona przylega do spoiny;

- metoda eliptyczna - badanie spoiny obwodowej o małej średnicy, źródło promieniowania znacznie oddalone od spoiny i przesunięte względem płaszczyzny spoiny, badanie dotyczy odcinka spoiny przyległego do błony oraz od strony źródła promieniowania.

W PN-EN ISO 17636-1 zawarte są wszystkie wymienione metody (układy) badań, a także dodatkowo układy do badań spoin króćców czy spoin pachwinowych. Porównanie tych metod zawarte jest w tablicy I.

W PN-M-69770 poza przedstawieniem metod badań nie podano szczegółowych wymagań dotyczących poszczególnych technik prześwietlania.

I tak:

- nie podano zakresu stosowania techniki eliptycznej (zakresu średnic i grubości ścianek rur, ilości ekspozycji);

- nie jest uwzględniona technika prześwietlania prostopa- dłego (Rysunek 12 normy PN-EN ISO 17636-1);

- brak jest wymagania oznaczania wskaźnika jakości obrazu literą „ $\mathrm{F}^{\prime \prime}$ w przypadku umieszczenia go od strony błony w przypadku technik dwuściennych;

- nie określono minimalnej liczby radiogramów, koniecznych do wykonania badania złączy obwodowych (Załącznik A normy PN-EN ISO 17636-1).

\section{Błony i okładki wzmacniające}

W PN-M-69770 podzielono błony radiograficzne, w zależności od czułości, kontrastowości i ziarnistości, na typy oznaczone rzymskimi liczbami od I do IV (Tablica 1). Błony niższego typu mają małą czułość i bardzo dużą kontrastowość a wyższego typu - bardzo dużą czułość i bardzo małą kontrastowość.

Dodatkowo w tablicy na stronie 8 (tablica ta nie ma swojego numeru) podano klasyfikację błon wybranych producentów w zależności od typu błony. I tak odpowiednikiem błony typu I jest między innymi błona Structurix D4 firmy Agfa, co odpowiada błonie klasy C3 wg PN-EN ISO 116991, zaś błonom typu II odpowiadają błony D5 (C4) i D7 (C5). I właśnie te typy błon zalecane są do stosowania w PN-EN ISO 17636-1.

W PN-M-69770 określono maksymalną gęstość optyczną zadymienia dla błon typu I i II na poziomie 0,2 i jest to mniej niż w PN-EN ISO 17636-1, wg której gęstość zadymienia może wynosić maksymalnie 0,3.

W Tablicy 2 PN-M-69770 podano zalecane grubości ołowianych okładek wzmacniających w zależności od źródła promieniowania. Wynika z niej, że najczęściej stosowane (zgodne z PN-EN ISO 17636-1) okładki przednie o grubości $0,05 \mathrm{~mm}$ oraz okładki tylne $0,1 \mathrm{~mm}$ spełniają wymagania dla promieniowania o napięciu do $250 \mathrm{kV}$, dla źródeł silniejszych należy stosować okładki grubsze. Pakowane fabrycznie błony gotowe do użycia z okładkami przednią i tylną o grubości 0,027 mm wg PN-M-69770 nie mogą być używane ze względu na minimalną grubość okładki tylnej.

Porównanie grubości ołowianych okładek wzmacniających przedstawiono w tablicy II.

\section{Jakość obrazu radiograficznego}

PN-M-69770 dzieli radiogramy wg jakości obrazu radiograficznego na klasy:

1 - klasa podwyższonej wykrywalności,

2 - klasa normalnej wykrywalności,

3 - klasa obniżonej wykrywalności.

O zakwalifikowaniu radiogramu do określonej klasy jakości obrazu radiograficznego decydują widoczne na nim elementy wskaźnika jakości obrazu o wymiarach podanych w tabeli 3, 4, 5 lub 6 normy, w zależności od rodzaju wskaźnika, miejsca jego umieszczenia oraz grubości materiału spawanego.

W PN-EN ISO 17636-1 rozróżnia się dwie klasy technik radiograficznych:

- Klasa A: techniki podstawowe,

- Klasa B: techniki ulepszone.

O zakwalifikowaniu radiogramu do poszczególnych klas decydują między innymi: widoczne elementy wskaźnika jakości obrazu, zastosowany system błon i okładek, odległość źródła od obiektu, maksymalny obszar pojedynczego naświetlenia, gęstość optyczna radiogramu. Porównując techniki wykonania radiogramu wg obu norm wzięto pod uwagę średnicę widocznych wskaźników jakości obrazu typu pręcikowego, tablica III i tablica IV. 
Tablica I. Porównanie układów badań norm PN-M-697700 i PN-EN ISO 17636-1

Table I. A comparison of the systems research standards PN-M-697700 i PN-EN ISO 17636-1

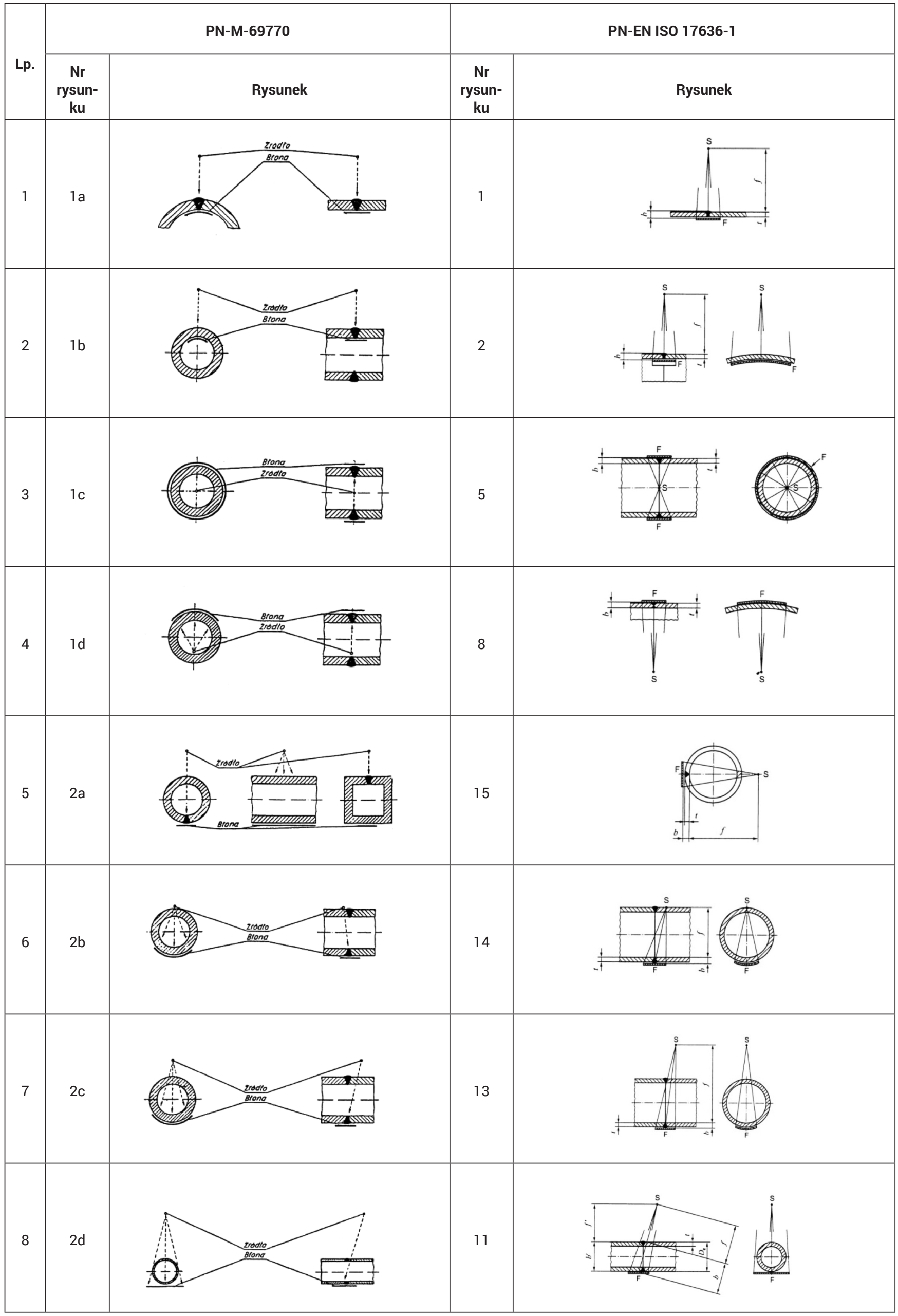


Tablica II. Porównanie grubości okładek wzmacniających

Table II. A comparison of thickness of reinforcement covers

\begin{tabular}{|c|c|c|c|c|c|}
\hline \multirow{2}{*}{ Lp. } & \multirow{2}{*}{$\begin{array}{l}\text { Napięcie źródła } \\
\text { promieniowania X }\end{array}$} & \multicolumn{2}{|c|}{$\begin{array}{c}\text { Grubość okładki wzmacniającej } \\
\text { wg PN-M-69770 }\end{array}$} & \multicolumn{2}{|c|}{$\begin{array}{c}\text { Grubość okładki wzmacniającej } \\
\text { wg PN-EN ISO 17636-1 }\end{array}$} \\
\hline & & przednia & tylna & przednia & tylna \\
\hline 1 & $\leq 100 \mathrm{kV}$ & $0,02 \div 0,05 \mathrm{~mm}$ & $\geq 0,10 \mathrm{~mm}$ & $\leq 0,03^{\mathrm{a}}$ & $\leq 0,03^{\mathrm{a}}$ \\
\hline 2 & $>100 \mathrm{kV}$ do $120 \mathrm{kV}$ & $0,02 \div 0,05 \mathrm{~mm}$ & $\geq 0,10 \mathrm{~mm}$ & $\leq 0,15$ & $\leq 0,15$ \\
\hline 3 & $>120 \mathrm{kV}$ do $150 \mathrm{kV}$ & $0,02 \div 0,15 \mathrm{~mm}$ & $\geq 0,10 \mathrm{~mm}$ & $\leq 0,15$ & $\leq 0,15$ \\
\hline 4 & $>150 \mathrm{kV}$ do $250 \mathrm{kV}$ & $0,02 \div 0,15 \mathrm{~mm}$ & $\geq 0,10 \mathrm{~mm}$ & $0,02 \div 0,15 \mathrm{~mm}$ & $0,02 \div 0,15 \mathrm{~mm}$ \\
\hline 5 & $>250 \mathrm{kV}$ do $400 \mathrm{kV}$ & $0,10 \div 0,15 \mathrm{~mm}$ & $\geq 0,15 \mathrm{~mm}$ & $0,02 \div 0,20 \mathrm{~mm}$ & $0,02 \div 0,20 \mathrm{~mm}$ \\
\hline
\end{tabular}

Tablica III. Porównanie wskaźników jakości obrazu przy prześwietlaniu przez jedną ściankę i wskaźniku IQI od strony źródła Table III. A comparison of the indicators of image quality in the radiograph by one wall and indicator IQI from the source side

\begin{tabular}{|c|c|c|c|c|c|c|c|c|c|c|c|}
\hline \multicolumn{6}{|c|}{ Klasa I wg PN-M-69770 oraz klasa B wg PN-EN ISO 17636-1 } & \multicolumn{6}{|c|}{ Klasa II wg PN-M-69770 oraz klasa A wg PN-EN ISO 17636-1 } \\
\hline \multicolumn{2}{|c|}{$\begin{array}{c}\text { Grubość } \\
\text { prześwietlana } \\
\text { mm }\end{array}$} & \multicolumn{2}{|c|}{ wg PN-M-69770 } & \multicolumn{2}{|c|}{ wg PN-EN ISO 17636-1 } & \multicolumn{2}{|c|}{$\begin{array}{c}\text { Grubość } \\
\text { prześwietlana } \\
\mathbf{m m}\end{array}$} & \multicolumn{2}{|c|}{ wg PN-M-69770 } & \multicolumn{2}{|c|}{$\begin{array}{c}\text { wg PN-EN ISO } 17636- \\
1\end{array}$} \\
\hline $\begin{array}{c}\text { po- } \\
\text { wyżej }\end{array}$ & do & $\begin{array}{c}\text { Średnica } \\
\text { pręcika } \\
\text { mm }\end{array}$ & $\begin{array}{l}\text { Wiel- } \\
\text { kość IQI }\end{array}$ & $\begin{array}{c}\text { Średnica } \\
\text { pręcika } \\
\text { mm }\end{array}$ & $\begin{array}{c}\text { Wielkość } \\
\text { IQI }\end{array}$ & $\begin{array}{l}\text { po- } \\
\text { wy- } \\
\text { żej }\end{array}$ & do & $\begin{array}{c}\text { Średnica } \\
\text { pręcika } \\
\text { mm }\end{array}$ & $\begin{array}{c}\text { Wielkość } \\
\text { IQI }\end{array}$ & $\begin{array}{c}\text { Średnica } \\
\text { pręcika } \\
\text { mm }\end{array}$ & $\begin{array}{c}\text { Wielkość } \\
\text { IQI }\end{array}$ \\
\hline & 1,5 & 0,100 & W16 & 0,050 & W19 & & 1,2 & 0,125 & W14 & 0,063 & W18 \\
\hline 1,5 & 2,5 & 0,100 & W16 & 0,063 & W18 & 1,2 & 2 & 0,125 & W14 & 0,063 & W18 \\
\hline 2,5 & 4 & 0,100 & W16 & 0,080 & W17 & 2 & 3,5 & 0,125 & W14 & 0,100 & W16 \\
\hline 4 & 6 & 0,125 & W15 & 0,100 & W16 & 3,5 & 4 & 0,125 & W14 & 0,125 & W15 \\
\hline 6 & 8 & 0,125 & W15 & 0,125 & W15 & 4 & 5 & 0,20 & W13 & 0,125 & W15 \\
\hline 8 & 11 & 0,125 & W14 & 0,125 & W14 & 5 & 7 & 0,20 & W13 & 0,125 & W14 \\
\hline 11 & 12 & 0,20 & W13 & 0,125 & W14 & 7 & 8 & 0,20 & W13 & 0,20 & W13 \\
\hline 12 & 16 & 0,20 & W13 & 0,20 & W13 & 8 & 10 & 0,25 & W12 & 0,20 & W13 \\
\hline 16 & 20 & 0,25 & W12 & 0,20 & W13 & 10 & 11 & 0,25 & W12 & 0,25 & W12 \\
\hline 20 & 25 & 0,25 & W12 & 0,25 & W12 & 11 & 15 & 0,32 & W11 & 0,25 & W12 \\
\hline 25 & 30 & 0,32 & W11 & 0,25 & W12 & 15 & 16 & 0,32 & W11 & 0,32 & W11 \\
\hline 30 & 32 & 0,32 & W11 & 0,32 & W11 & 16 & 25 & 0,40 & W10 & 0,32 & W11 \\
\hline 32 & 35 & 0,40 & W10 & 0,32 & W11 & 25 & 32 & 0,50 & w9 & 0,40 & W10 \\
\hline 35 & 40 & 0,40 & W10 & 0,40 & W10 & 32 & 40 & 0,63 & W8 & 0,50 & W9 \\
\hline 40 & 45 & 0,50 & w9 & 0,40 & W10 & 40 & 55 & 0,80 & W7 & 0,63 & W8 \\
\hline 45 & 50 & 0,50 & W9 & 0,50 & w9 & 55 & 60 & 0,80 & W7 & 0,80 & W7 \\
\hline 50 & 65 & 0,63 & W8 & 0,50 & W9 & 60 & 80 & 1,00 & W6 & 0,80 & W7 \\
\hline 65 & 80 & 0,63 & W8 & 0,63 & W8 & 80 & 85 & 1,25 & W5 & 0,80 & W7 \\
\hline 80 & 100 & 0,80 & W7 & 0,63 & W8 & 85 & 100 & 1,25 & W5 & 1,00 & W6 \\
\hline
\end{tabular}


Tablica IV. Porównanie wskaźników jakości obrazu przy prześwietlaniu przez dwie ścianki i wskaźniku IQI od strony błony Table IV. A comparison of the indicators of image quality in the radiograph by two walls and indicator IQI from the membrane side

\begin{tabular}{|c|c|c|c|c|c|c|c|c|c|c|c|}
\hline \multicolumn{6}{|c|}{ Klasa I wg PN-M-69770 oraz klasa B wg PN-EN ISO 17636-1 } & \multicolumn{6}{|c|}{ Klasa II wg PN-M-69770 oraz klasa A wg PN-EN ISO 17636-1 } \\
\hline \multicolumn{2}{|c|}{$\begin{array}{c}\text { Grubość } \\
\text { prześwietlana } \\
\mathbf{m m}\end{array}$} & \multicolumn{2}{|c|}{ wg PN-M-69770 } & \multicolumn{2}{|c|}{ wg PN-EN ISO 17636-1 } & \multicolumn{2}{|c|}{$\begin{array}{c}\text { Grubość } \\
\text { prześwietlana } \\
\text { mm }\end{array}$} & \multicolumn{2}{|c|}{ wg PN-M-69770 } & \multicolumn{2}{|c|}{ wg PN-EN ISO 17636-1 } \\
\hline $\begin{array}{c}\text { powy- } \\
\text { żej }\end{array}$ & do & $\begin{array}{l}\text { Śred- } \\
\text { nica } \\
\text { pręcika } \\
\text { mm }\end{array}$ & $\begin{array}{c}\text { Wielkość } \\
\text { IQI }\end{array}$ & $\begin{array}{c}\text { Śred- } \\
\text { nica } \\
\text { pręcika } \\
\text { mm }\end{array}$ & Wielkość IQI & $\begin{array}{c}\text { powy- } \\
\text { żej }\end{array}$ & do & $\begin{array}{c}\text { Średnica } \\
\text { pręcika } \\
\text { mm }\end{array}$ & $\begin{array}{c}\text { Wielkość } \\
\text { IQI }\end{array}$ & $\begin{array}{c}\text { Średnica } \\
\text { pręcika } \\
\text { mm }\end{array}$ & $\begin{array}{c}\text { Wielkość } \\
\text { IQI }\end{array}$ \\
\hline & 1,5 & 0,100 & W16 & 0,050 & W19 & & 1,2 & 0,125 & W14 & 0,063 & W18 \\
\hline 1,5 & 2,5 & 0,100 & W16 & 0,063 & W18 & 1,2 & 2 & 0,125 & W14 & 0,080 & W17 \\
\hline 2,5 & 4 & 0,100 & W16 & 0,080 & W17 & 2 & 3,5 & 0,125 & W14 & 0,100 & W16 \\
\hline 4 & 6 & 0,125 & W15 & 0,100 & W16 & 3,5 & 4 & 0,125 & W14 & 0,125 & W15 \\
\hline 6 & 8 & 0,125 & W15 & 0,125 & W15 & 4 & 5 & 0,20 & W13 & 0,125 & W15 \\
\hline 8 & 11 & 0,125 & W14 & 0,125 & W15 & 5 & 8 & 0,20 & W13 & 0,125 & W14 \\
\hline 11 & 12 & 0,20 & W13 & 0,125 & W15 & 8 & 10 & 0,20 & W13 & 0,125 & W14 \\
\hline 12 & 18 & 0,20 & W13 & 0,16 & W14 & 10 & 11 & 0,25 & W12 & 0,20 & W13 \\
\hline 18 & 20 & 0,20 & W13 & 0,20 & W13 & 11 & 15 & 0,32 & W11 & 0,20 & W13 \\
\hline 20 & 29 & 0,25 & W12 & 0,20 & W13 & 15 & 20 & 0,32 & W11 & 0,25 & W12 \\
\hline 29 & 30 & 0,32 & W11 & 0,20 & W13 & 20 & 22 & 0,40 & W10 & 0,25 & W12 \\
\hline 30 & 36 & 0,32 & W11 & 0,25 & W12 & 22 & 36 & 0,50 & w9 & 0,32 & W11 \\
\hline 36 & 45 & 0,40 & W10 & 0,25 & W12 & 36 & 38 & 0,63 & w8 & 0,32 & W11 \\
\hline 45 & 55 & 0,50 & w9 & 0,32 & W11 & 38 & 48 & 0,63 & W8 & 0,40 & W10 \\
\hline 55 & 65 & 0,50 & w9 & 0,40 & W10 & 48 & 50 & 0,63 & w8 & 0,50 & w9 \\
\hline 65 & 70 & 0,63 & W8 & 0,40 & W10 & 50 & 60 & 0,80 & W7 & 0,50 & w9 \\
\hline 70 & 100 & 0,63 & W8 & 0,50 & w9 & 60 & 70 & 0,80 & W7 & 0,63 & W8 \\
\hline & & & & & & 70 & 85 & 1,00 & w6 & 0,63 & w8 \\
\hline & & & & & & 85 & 100 & 1,00 & W6 & 0,80 & W7 \\
\hline
\end{tabular}

Wynika z tego, że klasie 1 obrazu radiograficznego odpowiada technika B, zaś klasie 2 - technika A, ponieważ wymagania co do widoczności odpowiednich pręcików w normie PN-EN ISO 17636-1 są ostrzejsze dla określonych grubości prześwietlanych blach.

\section{Dobór źródła promieniowania oraz warunków geometrycznych}

Norma PN-M-69770 określa dobór maksymalnego napięcia na lampie rentgenowskiej oraz minimalną odległość źródło-obiekt w zależności od grubości badanego elementu, rozmiaru źródła, typu błon i okładek wzmacniających, niezależnie od klasy jakości obrazu radiograficznego. Zaś w PN-EN ISO 17636-1 parametry ekspozycji (napięcie i odległość źródło-obiekt) nie są bezpośrednio uzależnione od klasy systemu błon okładek wzmacniających. Jednak analizując wykresy i nomogramy dotyczące dobierania wyżej wymienionych parametrów w obu normach, można zaobserwować, że PN-M-69770 zaleca stosowanie niższych napięć dla błon klasy C3 oraz wyższych dla błon C4, C5, rysunek 1 i większych odległości niż PN-EN ISO 17636-1 (w klasie B), rysunek 2. 


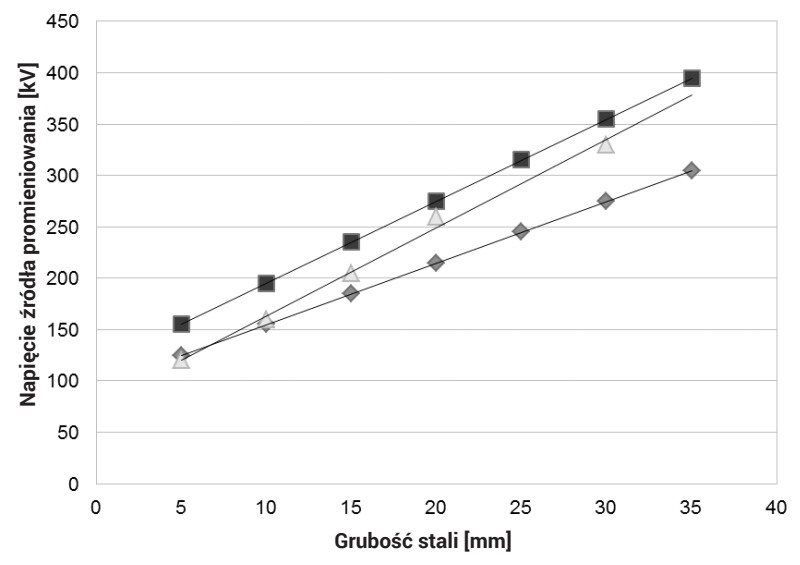

Rys. 1. Porównanie maksymalnych napięć w zależności od prześwietlanej grubości. Oznaczenia: I, II - maksymalne napięcia dla błon, odpowiednio typu I i II wg PN-M-69770, III - maksymalne napięcie wg PN-EN ISO 17636-1

Fig. 1. A comparison of maximum voltages depending on the overexposed thickness. Markings: I, II - maximum voltages for membranes, respectively type I and II according to PN-M-69770, III - maximum voltage according to PN-EN ISO 17636-1

\section{Dobór warunków ekspozycji}

Wymagana gęstość optyczna radiogramu wg PN-M69770 zależy od typu błony i okładek wzmacniających. Dla błon klasy I i II powinna zawierać się w zakresie od 2,0 do 3,0, jednak w przypadku zastosowania do przeglądania radiogramów negatoskopu pozwalającego na uzyskaniu na powierzchni radiogramu luminancji nie mniejszej niż $10 \mathrm{~cd} / \mathrm{m}^{2}$, dopuszcza się gęstości optyczne powyżej 3,0. Brak jednak informacji o maksymalnym dopuszczalnym zaczernieniu ocenianego radiogramu.

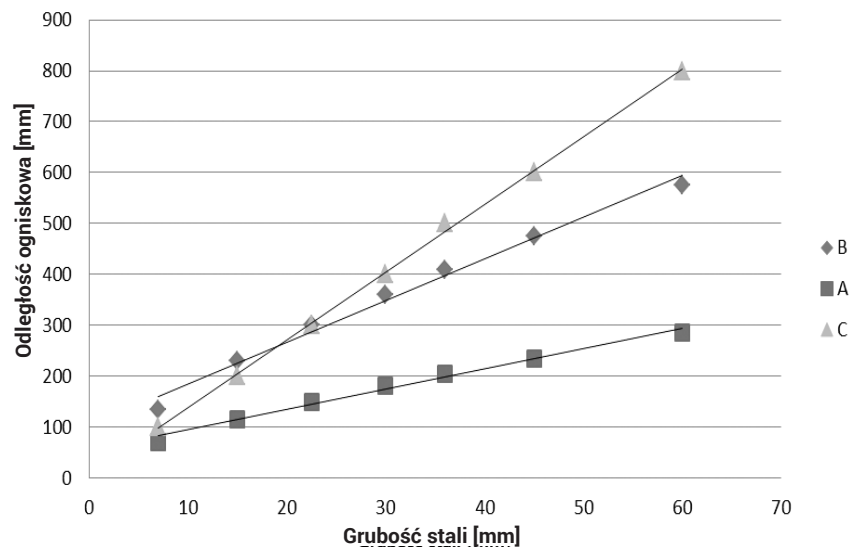

Rys. 2. Porównanie minimalnej odległości ogniskowej w zależności od prześwietlanej grubości. Oznaczenia: A, B - minimalna odległość ogniskowa dla klas, odpowiednio A i B wg PN-EN ISO 17636-1, C - minimalna odległość ogniskowa wg PN-M-69770

Fig. 2. A comparison of minimum focal distance depending on the radiographed thickness. Symbols: $A, B$ - minimum focal distance for class, respectively A and B according with PN-EN ISO 17636-1, C - minimum focal distance according with PN-M-69770

Warunki geometryczne ekspozycji powinny być tak dobrane, by zaczernienia w całym obszarze mieściły się w podanym zakresie.

Norma PN-EN ISO 17636-1 określa minimalne zaczernienie radiogramu w obszarze ocenianym w zależności od klasy badania: 2,0 dla klasy A lub 2,3 dla klasy B. Maksymalne zaczernienie jest ograniczone możliwościami będącego do dyspozycji negatoskopu.

Norma PN-M-69770 zaleca stosowanie minimalnej ekspozycji, która dla błon typu I wynosi 30 a dla błon typu II - 20, czego w PN-EN ISO 17636-1 nie ma.

\section{Wnioski}

Stosując normę PN-EN ISO 17636-1 w zastępstwie PN-M-69770 należy wziąć pod uwagę następujące rzeczy:

- obydwie normy zalecają podobne układy badań;

- obydwie normy dopuszczają stosowanie powszechnych na rynku ołowianych okładek wzmacniających, o grubości ołowiu 0,05 i 0,1 mm oraz pakowane fabrycznie błony gotowe do użycia z okładkami 0,027 mm;

- norma PN-EN ISO 17636-1 stawia ostrzejsze wymagania co do widoczności odpowiedniego pręcika wzorca IQI;

- minimalne odległości źródło-obiekt są na ogół większe dla PN-M-69770;

- norma PN-M-69770 dla błon klasy C4 i C5 wymaga stosowania niższych napięć niż PN-EN ISO 17636-1;

- zakres zaczernienia radiogramów wg obydwu norm pokrywa się.

\section{Literatura}

[1] Historia PKN w pigułce. Najważniejsze wydarzenia w historii Polskiego Komitetu Normalizacyjnego. http://www.pkn.pl/historia-pkn-w-pigulce-0

[2] PN-M-69770:1972 Radiografia przemysłowa - Radiogramy spoin czołowych w złączach doczołowych ze stali - Wymagania jakościowe i wytyczne wykonania.
[3] PN-EN ISO 17636-1:2013-06 Badania nieniszczące spoin - Badanie radiograficzne - Część 1: Techniki promieniowania $\mathrm{X}$ i gamma $\mathrm{z}$ błoną. 